\title{
3D-BIM and 4D-BIM Models in Construction Safety Management
}

\author{
Nguyen Quoc Toan ${ }^{1 *}$, Nguyen Thi Tuyet Dung ${ }^{2}$, and Nguyen Thi My Hanh ${ }^{1}$ \\ ${ }^{1}$ Faculty of Construction Economics and Management, National University of Civil Engineering, \\ Hanoi, Vietnam \\ ${ }^{2}$ Urban Management Faculty, Hanoi Architectural University, Viet Nam
}

\begin{abstract}
The application of modern technologies into on-site construction safety management has been proved that be successful. BIM technology which has been studied and developed for adopting widely in the construction industry is promised to bring significant improvements in construction safety management. The article reviewed the application of BIM in the management of construction safety, detailed for each safety work activity. Suggestions for selecting BIM tools in the management of construction safety are also listed. Lastly, the article poses some obstacles while applying BIM to construction safety management in Vietnam.
\end{abstract}

\section{Introduction}

Construction is one of the most dangerous industries due to outdoor and heavy work environment. It also depends on external factors and having high risk. In Vietnam, although the construction industry has made strong advances in engineering and technology, construction safety issues still exist. The rate of death and injury due to occupational accidents in the construction industry is twice as high as that of other industries [1]. Although construction safety issues have been paid more attention in recent years, the accident rate of the construction industry continues to remain high.

Ineffective safety training, inadequate and incomplete work planning and supervision and untimely information exchange about safety are the main issues of construction safety management. Currently, there have been a number of studies on improving safety through construction safety management, using Building Information Modeling (BIM). This model allows for the visual assessment of workplace conditions and identification of hazards. Construction planning simulation using $4 \mathrm{D}$ requires connecting to $3 \mathrm{D}$ objects in one design, simulating construction sequences as well as showing what construction works and ground will be combined at every point for each certain time. This simulation supports daily construction assessment, demonstrating problems of resource mobilization and adjustment options (grounds, labours, tools, spatial conflicts, safety issues, etc) [2].

\footnotetext{
* Corresponding author: toannq@nuce.edu.vn
} 


\section{Occupational safety in construction in Vietnam}

\subsection{Number of occupational accidents}

According to a report by the Ministry of Labour, Invalids and Social Affairs, from 2014 to 2018, the occupational accident situation has been complicated. In 2018, there were 7,997 occupational accident cases in Viet Nam, causing 8,229 people to be injured [3]. Although there have been many solutions to strengthen management, there are still many occupational accidents in the localities.

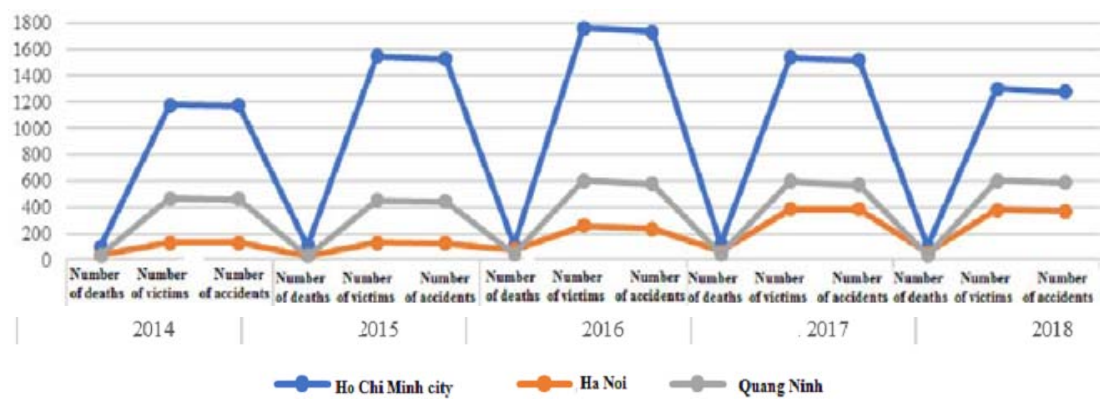

Fig. 1. Occupational accident situation from 2014 to 2018 in some Vietnamese localities (Source: [3]) The provinces have many people died from occupational accidents are Ho Chi Minh City, Hanoi, Quang Ninh.

\subsection{Comparison of occupational accident situation from 2014-2018}

Statistics on the occupational accident situation in the years from 2014 to 2018 specifically as follows:

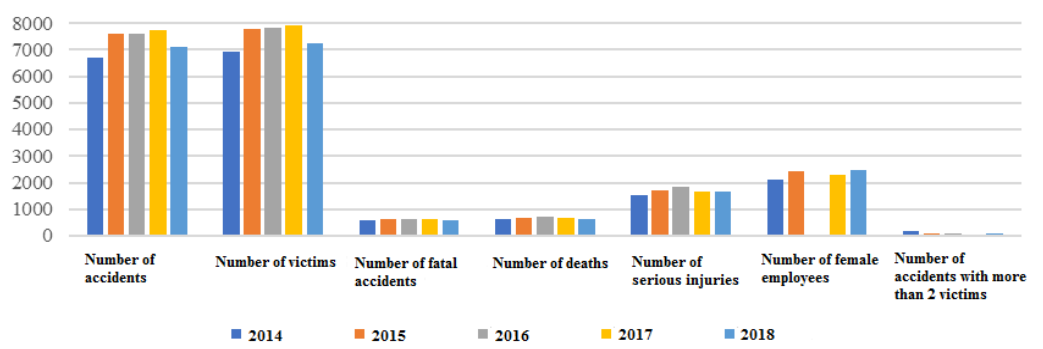

Fig. 2. Occupational accident situation from 2014-2018 in the industrial relations areas in Viet Nam (Source: [3])

Through above statistics, it can be seen that the number of occupational accidents in production is still quite large, although the occupational accidents in 2018 has decreased compared to these in 2017 and 2016.

Table 1. The occupational accident rate from 2014-2018 in the construction sector

\begin{tabular}{|c|c|c|}
\hline Year & Accident rate & Mortality rate \\
\hline 2014 & $33.10 \%$ & $33.90 \%$ \\
\hline 2015 & $35.20 \%$ & $37.90 \%$ \\
\hline 2016 & $23.80 \%$ & $24.50 \%$ \\
\hline 2017 & $20.80 \%$ & $19.70 \%$ \\
\hline 2018 & $15.79 \%$ & $15.57 \%$ \\
\hline
\end{tabular}

(Source: [3]) 
Analyzing from the survey records of fatal occupational accidents received in 2018, it can be found that the rate of occupational accidents in the construction sector has decreased, but it is still the area where the most occupational accidents and deaths occur.

The main factors causing the most mortality rates in construction include:

- The person falling from height accounts for $14.91 \%$ of the total number of accidents and $14.75 \%$ of the total number of deaths;

- The falling objects accounted for $14.91 \%$ of the total number of accidents and $16.39 \%$ of the total number of deaths;

- Electric shock accounts for $10.53 \%$ of the total number of accidents and $9.84 \%$ of the total number of deaths;

- The rolling and clamping machines and equipments accounted for $10.53 \%$ of the total number of accidents and $9.84 \%$ of the total number of deaths;

- The objects splashed from construction accounted for $4.39 \%$ of the total number of accidents and $4.1 \%$ of the total number of deaths.

In addition to damage to health and life, physical damage also amounted to trillions of dong (VND). In 2017 alone, it was VND 1545.8 billion, not to mention the loss due to occupational accidents which was 136,918 working days [3].

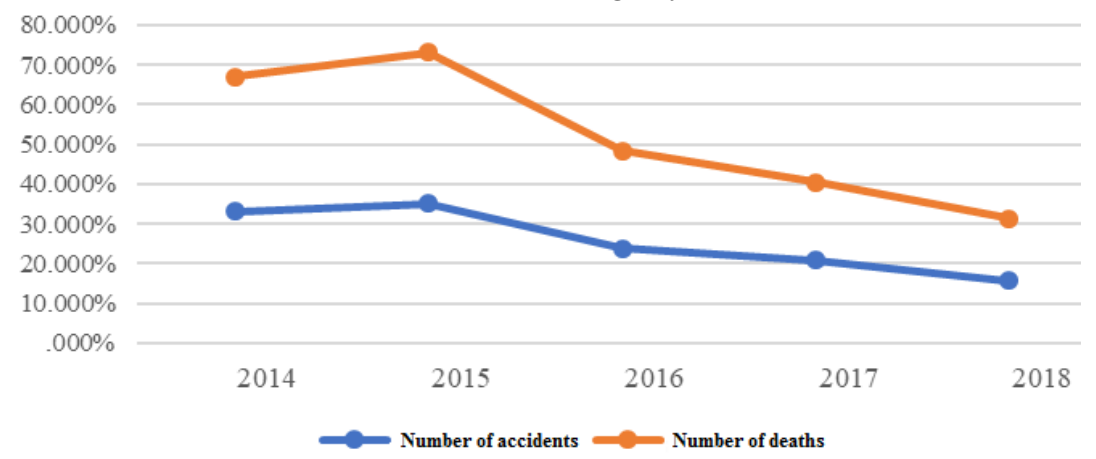

Fig. 3. Occupational accident situation from 2014 to 2018 in the construction sector (Source: [3])

Obviously, construction occupational accidents in Vietnam are a painful problem, requiring advanced safety management methods and technologies to solve that situation.

\section{Concept of BIM, 3D-BIM and 4D-BIM}

\subsection{Concept of BIM}

The concept of BIM, which is widely used in both research documents and industry, is the information system of asset lifecycle, construction product modeling, integrated design system, integrated project delivery, virtual model, virtual construction, virtual design and 4D Product Model [4].

BIM technology opens up the connecting possibility between 3D building model and other project informations such as schedule (4D-BIM model), cost (5D-BIM model), used energy simulation approaches, construction stabilization, construction maintenance and sustainable development to form the BIM $\mathrm{nD}$ expansion model [5], [6].

\subsection{Concept of 3D-BIM and 4D-BIM}

In order to apply BIM in construction safety management, 3D and 4D-BIM models are most widely used. 3D-BIM model is evaluated as a "smart" 3D model that can be linked 
with construction progress to create 4D-BIM progress model. While 3D AUTOCAD software only allows drawing components with geometric dimensions, 3D-BIM models can create components with attached attributes. The attributes of a component are linked and dependent. When an information changes, the relevant informations are automatically changed based on their dependence. These changes can be made at any time and at any position during the project such as drawings, sections, progress, 3D views.

3D-BIM model is made up of different component groups such as layers of wall, column, beam, floor, etc. Each group of components is made up of many components with the same function, identified by IDs and listed into a list of small components [7].

4D-BIM is the connection between the $3 \mathrm{D}$ building model and the construction schedule of the "3D + Time" project. 4D-BIM provides visuals that simulate the construction process over time. The components are connected to the work items corresponding to the construction sequence. With virtual construction and work breakdown structure, "structured by components" clearly helps to better understand the project; detecting possible errors and risks to have appropriate plans; detecting unreasonable points in construction schedules and plans. Thereby, it is possible to reduce/ eliminate the unsafe factors.

To be compatible with the 3D model, the construction schedule must be established into respective work items. Each mini work is identified by its unique ID. Through the ID, it is possible to access and know all the attributes of a component and that work item. Based on the common IDs, the components in the 3D BIM model are connected to the respective work items. Thereby, work items and components are displayed on an intermediate interface, it is completely observable that they both launch on the same interface.

\section{Application of BIM for construction safety management}

In construction safety management, 3D and 4D-BIM are used as a complete, detailed, visual and digital input source for project information for other processing technologies and software. The applications of 3D and 4D-BIM in construction safety management can be summarized in four areas: Safety training, hazard identification, on site monitoring, communication and cooperation.

Construction safety training

The effectiveness of construction safety training will be significantly improved when the construction is visualized and allows employees to interact and cooperate on the construction model that they will participate in building. Many researchers have used BIM as a main tool and combined with VR (Virtual Reality) technology, a game technology for safety training. BIM and VR have been combined to create a virtual construction site to support safety training. Interoperability and collaboration of this training method are increased through the integration of BIM and online gaming technology, where workers can carry out their activities by using a computer connected to the Internet and they can communicate and collaborate with each other in real time.

Figure 4 shows the integration of construction process data into the combined 4D-BIM model to create a simulation of the construction processes. Based on 4D-BIM model, construction teams can perform simulations of different options in a virtual environment until a satisfactory method is found [7]. 


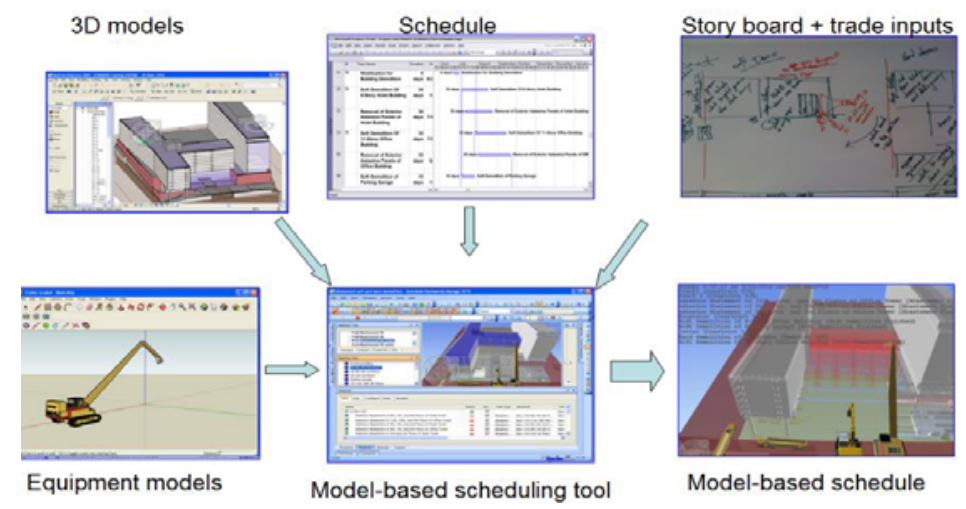

Fig. 4. 4D simulation process (source [7])

\section{Identification of unsafe hazards in construction}

3D-BIM can be used to assist safety staffs in identifying hazards during safety meetings. To automate the hazard identification process, studies were conducted to encode provisions of the law on labor safety and use BIM as a source to obtain information about structures, hazardous positions, and construction schedule in order to identify hazards through an automated rule checking system. Previously, only information about the project was considered in the hazard identification process. New studies have proposed additional information related to construction sites, warehouses, temporary houses, equipment, etc. which can assist in the comprehensive identification of hazards [8], [9].

4D-BIM provides both time and space of activities to increase the accuracy of potential conflict determination. Building structures and temporary construction structures such as scaffolding can also be potential hazards because they need to be stable enough to avoid collapsing during and after construction. 4D CAD, BIM and structural analysis software have been integrated to simulate and analyze the possible collapse [6]. When BIM is integrated with oxygen and temperature sensors, information about hazardous environments can be identified and marked in the virtual model.

\section{On site construction supervision}

Information on the location of workers, construction machinery and construction materials on site received from positioning technologies such as RFID, GIS, and GPS and transferred to the BIM model will enable visualization of tracking potential crash cases in real time [10].

\section{Exchange and cooperation in construction management}

BIM allows for easier communication and dissemination of information by overcoming language boundaries that exist in multinational construction projects. Building the visualization of information makes accessibility of information the same for everyone regardless of position, ability to read or understand language. BIM models can be the general-purpose means of communication such as helping to discuss the construction process among experts or informational workshops for project stakeholders. This approach can also make construction processes easier to understand for people who have no background in construction [11].

BIM contains logical relationships in terms of space, dimensions, quantity, materials and building components. It helps to integrate physical information about building components with other information (materials, construction schedule, etc.) in order to optimize design, construction, building operation management and maintenance. BIM is a source of storage and information to provide a solid basis for decision-making throughout the life cycle of a construction work [3]. This process allows for the coordination of subjects from many participating units in many different phases of the project. 


\section{Selection of suitable BIM modeling tools for construction safety management}

The most important features of BIM modeling software in construction safety management are: (1) 3D model quality and the ability to observe objects; (2) landscape modeling tools; (3) extensive 3D object library; (4) 4D-BIM creation tools and features; (5) tools for risk analysis or construction safety from planning design, (6) ability to exchange data.

\subsection{D modeling quality and color selection}

Structural models often have different colors. The colors of the components represent their structural attributes and colors can be assigned subjectively by the manager. However, in some cases, such as communication and presentation of security issues, the models should be as realistic as possible to quickly deliver messages that are easy to understand. On the other hand, it is necessary to highlight problems in the model by using contrasting colors, e.g. unrelated parts to set the background color and highlight key issues by using bright colors, in contrast to selected background color. That is why the software needs to allow users to choose colors without limitation in the color range.

\subsection{Tools for modeling landscapes and topography on site}

Currently, topographic data is increasingly being provided with the support of GIS and 3D laser scanning technology. From the viewpoint of construction safety, the softwares and equipments to support BIM modeling accurately describe topographic conditions, temporary bench mark elevation of ground and of structures in each construction stage, helping to save more time and limit errors.

\subsection{Extensive 3D object library}

Each building is built from component parts; each part is made up of many elements and objects. For the BIM model, these objects are called BIM Objects (BIM Components). These are the basic elements to create a model; it carries full geometric and non-geometric information, serving the process of design and construction, etc. Design softwares applying BIM allow users to manually create BIM Objects suitable for their projects such as creating a Family in Revit; Components in ArchiCAD, Sketchup; Part Builder in Civil3D, etc. If there are 3D objects available in the application (of most commonly used construction equipments on site), it will facilitate construction safety planning.

\subsection{Safety or risk analysis tools in construction}

Currently, there are almost no independent suitable tools to analyze construction safety using BIM. However, it is possible to integrate some safety hazard analysis techniques in the 4D-BIM model for analysis of risk and construction safety.

JHA (Job Hazard Analysis) is recommended by OSHA (The Occupational Safety and Health Administration) for construction activities to highlight and respond to potential hazards or JSA (Job Safety Analysis). Job hazard analysis is a technique that focuses on the steps of performing a job to predetermine potential hazards. JHA focuses on the relationships between the workers, jobs, tools, and the working environment. Implementation of the JHA will help identify hazards and gradually eliminate or reduce hazards to an acceptable level before construction [9]. 
The method of analyzing occupational safety hazards through the support of virtual construction site model was developed by Kiviniemi (2011). 4D-BIM is recognized as the central technology for the on-site construction safety planning, allowing for the visualization of safety arrangements in construction projects at different times [11].

The GIS technology for scheduling construction projects under the Critical path method (CPM) and connecting its activities with the corresponding components of the 3D BIM model has been developed by Bansal (2011). This connection makes it possible for managers to detect incomplete and logical errors in the project schedule. The GIS database management capabilities are also used to maintain and update the construction database (type and quantity of materials, labor requirements, recommendations on quality and safety control, etc.) in order to facilitate the construction project. This helps to warn of positions and jobs with high risk of occupational accidents, which are linked with the schedule [12].

The DFSP (Design For Safety Process) tool was developed by Hadikusumo (2004) to assist managers in detecting occupational accident hazards corresponding to construction components and processes. The DFSP database includes types of components, occupational accident hazards and early warning database [13].

\subsection{D tools for construction safety management in construction}

The softwares should have available tools/ procedures to make the temporary site arrangements such as safety equipments. Moreover, the ability for the users to choose the accuracy of a 4D image (steps between the stages are visualized) and the ability to choose an expression rule (which is somewhat represented and the corresponding color) in a 4D image are relevant features from a safety viewpoint.

\subsection{Data exchange}

BIM software has ability to import a model from other software, especially using the IFC file format and ability to export data in the IFC format to combine and use the models in other BIMbase software. Other usable file formats include $3 \mathrm{~d}-\mathrm{dwg}$. The shapes of one model can be integrated and used in another model in $3 \mathrm{~d}-\mathrm{dwg}$ format but it does not contain any smart product or information such as IFC file.

The popular softwares for establishing 3D-BIM model today include: Google SketchUp (Google), ArchiCAD (Graphisoft), Tekla Structures and Tekla Construction Management (Tekla), Navisworks (Autodesk) and Solibri Model Checker (Solibri Inc.). They are considered feasible for use in construction safety planning because safety should be considered at the design stage. Models created in the design stage are used in the construction stage as an information source or basis for production planning with the support of similar or compatible softwares. Moreover, the person who is responsible for construction safety planning is not willing to use multiple separate softwares in his/her construction projects.

Both Tekla's softwares include 4D tools. Another special advantage of using Tekla software for construction safety planning is the opportunity to use the structural model of the building as the basis for the construction safety planning. This model corresponds to construction on site. However, further Research and Development are needed to find out how to apply the selected software for the proposed safety-related purposes.

The strengths of architectural modeling software such as ArchiCAD and Revit include the suitable tools for landscape modeling and visualization of elevations under the construction plan, and one weakness is the lack or limitation of 4D features. Google SketchUp has gained a relatively high popularity in professional use. In the U.S, a number of contractors have also used it for construction safety planning and project communication 
assistance (Google Sketchup 2010). Google SketchUp is popular because of its low cost, easy to use, visualization of elevations under the construction plan and support for easy sharing of 3D components modeled by users with the help of Internet-based 3D Warehouse. Besides, another special feature is the opportunity to transfer 3D models of buildings onto Google Earth.

The BIM used on site can be a combination model such as with the support of Navis Works software or the Solibri model tester. BIM does not include any modeling tools but it can be used to combine models of different design parties in order to create combination models with a fairly small file size, considering building designs, checking for conflicts and creating visualization.

Currently, there are many different BIM solutions in Vietnam. However, there are only a number of solutions that are commonly used and each may or may not be appropriate during different project phases.

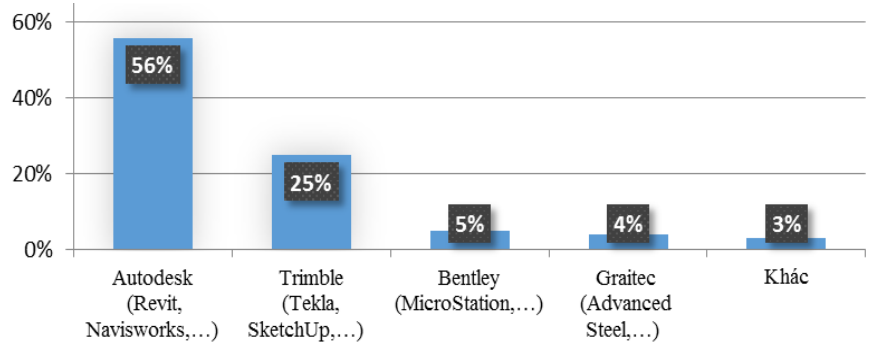

Fig. 5. Application rate of BIM solutions (Source [7])

The selection of tools for construction safety planning depends on reality, for example what types of models are taken from designers, what skills and tools are owned by the contractor/ person making the construction safety plan and how to use the model results. Construction safety planning is often based on a BIM architectural or structural models but the other way is combining the models as the basis for the construction safety plan or making from scratch.

\section{Challenges in applying BIM to manage construction safety in Vietnam}

\subsection{Legal issues}

Building information models are often created by experts with a variety of software programs and used by different parties. Errors in the use of building model information can lead to significant harm. Making complaints will become very complicated due to unclear rules of responsibility. In addition, the regulations on access and information security in building models, data ownership and protection, insurance, protocol [5], etc are not strict.

The lack of a legal framework makes all parties very careful when applying BIM. The application of BIM needs time for the best work performance. Therefore, before having the Government's support, enterprises will consider in whether to "risk" investing resources in BIM or not. Some contents related to BIM have been mentioned in the Construction Law 2014. This can be seen as a step forward in the application of BIM in Vietnam [14]. In addition, the State needs to publish specific BIM standards and guides to meet with the socio-economic conditions in Vietnam for enterprises applying BIM.

Vietnam can learn from the experiences of developed countries. The United Kingdom is a pioneer and a leader in the application of BIM in the construction industry. BIM standards 
and guides in the UK have been issued in most of the construction contents through the PAS 1192 standard on BIM application, including the PAS 1192-6 - 2017 standard on occupational safety using BIM.

\subsection{Technology}

BIM-based softwares also known as BIM tools have a number of problems such as incomplete development, lack of standards and protocols, etc. The limitation of BIM-based softwares is the major problem that limits its applicability in the construction industry in general and in construction safety management in particular. When applying BIM to make construction safety plans, there are still a number of limitations. For example, 3D-BIM modeling software lacks objects related to safety measures such as anti-falling nets, different types of scaffolding, etc.

BIM tools have not been able to fully provide all the different structural shapes and simulate information about hazards (electricity, use of labor equipment, sanitation, fire and explosion, etc.). Therefore, it is necessary to coordinate many solutions in the modeling process or to model it manually. To overcome this, cooperation in building a diversified library system is required.

\subsection{Cost}

The cost of BIM application is also a major barrier. The main costs include the cost of software as well as hardware, training, etc. According to the survey of McGraw-Hill in 2008, cost and training issues are the biggest barriers to the application of BIM in construction. In Vietnam, expenditure for BIM application is an important reason that companies do not dare to invest, up to $29 \%$ of respondents said that the cost for BIM applications is too large, which is the reason why BIM has not been applied at the enterprises [7].

\subsection{Management}

Management refers to the process and organization including the attitudes of stakeholders, the lack of success cases and related management standards, the fragmented nature of the construction industry, the nonconformity of business models and lack of cooperation from partners. Fragmentation is always a big issue affecting the productivity and performance of a construction project. However, one study [15] suggested that most units hesitate to use BIM mainly because of the fragmented nature of the construction process and the difference of each project.

\subsection{Human resource}

Implementing construction safety management using BIM needs to use 3D and 4D models. Although designers are capable of modeling and have the necessary software, most of them have no practical knowledge of construction safety. On the other hand, the disjointed interaction between stakeholders, especially between design consulting units and construction contractors and the disruptions between the investment phases in Vietnam make the efficiency of communication and cooperation in building BIM model in construction safety management difficult. Therefore, promoting awareness and participation of all stakeholders is essential. 


\section{Conclusion}

Construction Safety management based on 4D-BIM model instead of a safety plan using 3D-BIM model has the potential to implement the safety plan in real time and connect the safety plan with construction plan.

In order to complete construction safety management with the support of BIM technology, tools and working methods need to be further developed. Moreover, it's necessary to have more practical experience in safety planning by using BIM and build capacity to use BIM methods and tools in construction projects.

\section{References}

1. S. Vitor, A. Nuno M, D. Luís A, Risk-based management of occupational safety and health in the construction industry-Part 1: Background knowledge, Safety science, 66: 75-86 (2014)

2. B. Gledson, D. Greenwood, The implementation and use of $4 D$ BIM and virtual construction, Procs 30th Annual ARCOM Conference, Portsmouth, UK, 673-682 (2014)

3. N. Q. Toan et al., The barriers of lean construction practices to minimize occupational accidents in construction, Vietnam Journal of Construction, No. 12, 108-113 (2019)

4. S. Bilal, Building information modeling framework: A research and delivery foundation for industry stakeholders, Automation in construction, 18(3): 357-375 (2009)

5. M. Ibrahim, A. Abdulkareem, A knowledge-based BIM system for building maintenance, Automation in construction, 29, 173-182 (2013)

6. J. P. Zhang, Z. Z. Hu, BIM-and 4 D-based integrated solutions of analysis and management for conflicts and structural safety problems during construction: 1. Principles and methodologies, Automation in construction, 20 (2): 155-166 (2011)

7. N. V. Hung, T. N. Binh et al., Report of Research project on Development of a BIM application roadmap in Vietnam for improving the efficiency of building design, construction and management, Institute of Construction Economics, Ministry of Construction (Vietnam), No. RD 03-14 (2015)

8. H. Malekitabar et al., Construction safety risk drivers: A BIM approach, Safety Science, 82, 445-455 (2016)

9. S. Zhang, F. Boukamp, J. Teizer, Ontology-based semantic modeling of construction safety knowledge: Towards automated safety planning for job hazard analysis (JHA), Automation in Construction, 52: 29-41 (2015)

10. M. Golparvar-Fard et al., D4AR-a 4-dimensional augmented reality model for automating construction progress monitoring data collection, processing and communication, Journal of information technology in construction, 14(13): 129-153 (2009)

11. Kiviniemi et al., BIM-based safety management and communication for building construction, VTT Tiedotteita - Research Notes 2597, VTT Technical Research Centre of Finland (2011)

12. V. K. Bansal \& P. Mahesh, Construction Projects Scheduling Using GIS Tools, International Journal of Construction Management, 11(1), 1-18 (2011)

13. B. Hadikusumo, S. Rowlinson, Capturing Safety Knowledge Using Design-for-SafetyProcess Tool, Journal of Construction Engineering and Management, 130 (2) (2004)

14. National Assembly, Construction Law No. 50/QH13/2014, approved by National Assembly term XIII on 18/6/2014 (2014)

15. R. Collins et al., Integration of safety risk factors in BIM for scaffolding construction, International Conference on Computing in Civil and Building Engineering, 307-314 (2014). 